\title{
Университет и Академия
}

М.П. ФЕДОРУК, ректор Новосибирского государственного университета

Ключевые слова: образование, Новосибирский государственный университет

Сибирское отделение РАН

- Михаил Петрович, мы сегодня не случайно возвращаемся к теме развития образования и НГУ, затронутой в самом первом номере «ЭКО». Тогда, в 1970-х, или поиски места образования и науки в современном мире, форматировалась модель взаимоотношений Академии наук и университета. Сейчас, по сути, происходит то же самое. Отсюда вопрос - что из идей основателей университета остается актуальным для нынешнего НГУ? От чего пришлось отказаться, что только сегодня назрело в повестке дня?

М.П. ФЕДОРУК: - Действительно, по многим вопросам, стоявшим перед отцами-основателями, мы вернулись на круги своя. Это и многоуровневое образование, и расширение фундаментальной подготовки инженеров - здесь можно назвать проект организации инженерной магистратуры на базе НГУ, и новый уровень взаимоотношений НГУ и Сибирского отделения РАН. Я читал стенограмму самого первого заседания ученого совета НГУ, где первый ректор - академик И. Я. Векуа - прямо говорит о том, что именно Сибирское отделение построило университет и должно им управлять.

Сегодня в связи с последними реформами в Министерстве образования и в Академии наук вопрос формализации взаимоотношений НГУ и СО РАН снова встает в повестке дня очень остро. Нам необходимо сохранить и развить ту тесную интеграцию с Сибирским отделением, которую завещали нам отцы-основатели, 
но, очевидно, в каком-то новом качестве. Тем более что и СО РАН сейчас меняет формат в связи с реформой. Мне кажется, что университет может стать неким центром интеграции для Сибирского отделения. Не в том смысле, чтобы присоединить к себе его институты - Боже упаси. Но местом встречи, площадкой для совместных проектов, в том числе междисциплинарных, для совместного выхода во внешнюю среду. У меня на столе сейчас лежат несколько договоров с институтами СО РАН, в которых оговариваются рамки возможного сотрудничества. Тоже, кстати, примета времени: раньше НГУ заключал один договор - с Сибирским отделением РАН и по нему жил, теперь - с каждым институтом в отдельности. То есть на практике мы уже выступаем неким интеграционным центром для институтов.

К слову, практически все проекты, которые мы реализуем совместно с институтами СО РАН, имеют интеграционный характер. Это и старые наши проекты, как, например, работа выпускающих кафедр: из 119 таких кафедр НГУ 85 находятся в институтах СО РАН; и новые - это, прежде всего, научно-исследовательские лаборатории.

В настоящее время созданы 73 лаборатории: совместные, коллаборационные, флагманские, зеркальные. Особые ожидания у нас связаны с четырьмя междисциплинарными исследовательскими центрами в области перспективных научных направлений: физики элементарных частиц и астрофизики; квантовым, прикладного анализа поведения, а также перспективных биомедицинских исследований. Междисциплинарные центры представляют новое направление деятельности, которое опирается на положительный опыт интеграционных проектов СО РАН. В НГУ такие центры призваны не только развивать новые научные направления, но и создавать современные образовательные программы и готовить студентов, используя опыт большого коллектива исследователей, российских и зарубежных. Это соответствует современным тенденциям в европейском высшем образовании, где создаются аналогичные сетевые структуры.

Конечно, мы будем развивать какие-то направления, которые не представлены в Сибирском отделении, но ставку все-таки делаем на развитие уже имеющейся базы. Это наше основное конкурентное преимущество, которое надо использовать для развития и университета, и СО РАН. 
- На последнем заседании наблюдательного совета НГУ прозвучала информация о готовящейся реформе структуры университета. В чем она заключается?

М.П. ФЕДОРУК: - На данном этапе структура меняется главным образом в гуманитарном блоке. В планах - создание при НГУ трех институтов. Один объединит гуманитарный факультет с факультетами журналистики и иностранных языков. Второй, который бы я условно назвал институтом фундаментальной медицины и психологии, объединит два соответствующих факультета. Третий - институт философии и права. Директора соответствующих институтов будут полностью подотчетны ректорату. В течение ближайших двух-трех лет изменится алгоритм взаимоотношений и с другими факультетами. Наша задача - сделать административную структуру университета более мобильной, прозрачной и управляемой.

- Здесь напрашивается вопрос о совместителях. Известно, что сформировать команду из людей, которые получают основной доход в другом месте и де-юре тебе не подчиняются, очень сложно. Между тем количество совместителей на некоторых кафедрах доходит до 80-90\%. Какие у вас как у ректора есть механизмы, рычаги влияния для консолидации коллектива?

М.П. ФЕДОРУК: - Это все связано с формализацией отношений с СО РАН. Обсуждалось множество вариантов, включая самые радикальные. Например, вариант жесткой интеграции придание единого юридического статуса всей структуре, существующей на территории новосибирского Академгородка: создание Лаврентьевского центра, некоего супер-университета наподобие Московского и Санкт-Петербургского. Но, конечно, подобного рода идеи могут быть осуществлены только «сверху», ведь мы даже относимся к разным ведомствам - ФАНО и Минобрнауки. В конце концов мы все-таки пришли к тому, что реализуем сейчас: пытаемся сделать площадку НГУ привлекательной для институтов, мотивировать их к консолидации вокруг общих задач.

Каким образом? Например, мы можем предоставлять некие льготы для научных проектов, проводимых через университет; можем выступать соучредителем лабораторий, ведущих научных журналов. Можем организовать на базе университета что-то вроде центра коммерциализации, трансфера технологий. Над всем этим мы сейчас плотно работаем... 
- Со времен СССР ситуация в СО РАН и Новосибирске коренным образом изменилась, - вступает в разговор главный редактор журнала «ЭКО» В.А. КРЮКОВ. - Тогда, помимо М.А. Лаврентьева с его харизмой, ученых в новосибирский Академгородок и НГУ влекла возможность реализации крупных интересных задач, в том числе на стыке фундаментальной и прикладной науки - для предприятий всесоюзного масштаба, которые здесь дислоцировались. Сейчас крупных предприятий в Новосибирске нет, как и в большинстве сибирских городов. Существуют в основном подразделения федеральных компаний, у которых нет ни инвестиционных полномочий, ни возможностей как-то взаимодействовать с фундаментальной наукой. Им требуется лишь решение текущих сиюминутных проблем, что, конечно, совершенно не соответствует потенциалу такого мощного научно-образовательного комплекса, которым является СО РАН и НГУ. Поэтому глобальной задачей, на мой взгляд, является некая интеграция СО РАН и НГУ с целью мощного выхода на федеральные и глобальные рынки научно-технических услуг и научно-технической продукции.

М.П. ФЕДОРУК: - Да, это так. К сожалению, в Новосибирске нет ни одной крупной госкорпорации, которая могла бы стать для нас равновеликим партнером. Мы гордимся своими высокотехнологичными предприятиями, своим Академпарком, в которых львиную долю занятых составляют выпускники НГУ. Но все это, по большому счету, - мелкий и средний бизнес. Для того чтобы они могли предъявить достаточно серьезный спрос, соответствующий нашему потенциалу, нужны годы и годы активного роста.

- Могут ли посодействовать в привлечении крупных заказчиков члены наблюдательного совета, выпускники НГУ из числа крупных бизнесменов?

М.П. ФЕДОРУК: - Определенные планы и надежды мы связываем и с теми, и с другими. Например, по постановлению № 218 у нас сейчас реализуется проект с компанией «Сигнатек»².

\footnotetext{
${ }^{2}$ Совместный проект НГУ иООО «Сигнатек» «Разработка аналитического программного комплекса потоковой обработки данных в телекоммуникационных сетях с целью обеспечения информационной безопасности» в 2015 г. победил в конкурсе Минобрнауки по развитию кооперации вузов и индустриальных партнёров. В рамках проекта НГУ будет выполнять научно-исследовательские работы в качестве головного исполнителя по приоритетному направлению развития науки, технологий и техники в РФ «Информационно-телекоммуникационные системы».
} 
Ведем переговоры с председателем наблюдательного совета С. Белоусовым по привлечению сюда инвестиций, и он уже открыл здесь центр разработок компании Parallels. Но все это идет не быстро и в масштабах, совершенно недостаточных для создания массового спроса.

В.А. КРЮКОВ: - Для этого здесь нужны не «Сигнатек» и не Parallels, при всем уважении, а именно глобальные игроки. Нужны научно-технические центры или госкорпораций, или крупных азиатских игроков: корейских, японских компаний.

М.П. ФЕДОРУК: - В Академгородке уже более 10 лет функционирует Центр разработок и исследований компании «Интел», и несколько моих аспирантов там даже успели поработать. Есть совместная лаборатория «НГУ-Intel». Но, во-первых, она небольшая - всего несколько десятков человек. Во-вторых, инвестиции там довольно скромные и за пределы лаборатории не выходят: в 2015 г. их объем составил примерно 1,7 млн руб. В-третьих, совмещать работу в подобной корпорации с научной деятельностью очень сложно - там свои задачи, у ученых - свои. Кстати, мои аспиранты, несмотря на высокие зарплаты в «Интел», через некоторое время вернулись в университет - заниматься наукой. То есть, по большому счету, кроме имиджевой составляющей, никаких особых материальных благ подобное сотрудничество пока не приносит.

Наверное, здесь нужны не столько филиалы или подразделения, сколько прямые заказы на услуги, НИОКР, наподобие того, что выполняют отдельные наши институты для «Роснефти», «Роскосмоса» и т. д. Мы тоже будем прилагать к этому усилия. Но пока по постановлению № 218 у нас было всего два гранта с коммерческими структурами, видимо, компаниям такое сотрудничество не очень интересно. Так что нашим основным заказчиком остается опять-таки государство - через систему грантов.

В.А. КРЮКОВ: - Один из возможных вариантов привлечения крупных инвесторов для загрузки имеющегося потенциала - это организация зоны технико-внедренческого типа, с особым статусом для крупных компаний. А одно из очевидных для НГУ масштабных и емких научных направлений - разработка минерально-сырьевой базы на севере страны - то, что нам близко географически и по духу. Именно по такому пути пошли научно-образовательные комплексы Аляски, канадской провинции Альберта, Дании, Норвегии. С этой точки зрения 
того, что до сих пор делалось и делается в НГУ и СО РАН, на мой взгляд, недостаточно. Сибирское отделение только начало к этому приближаться в конце 1980-х годов... Но тут, конечно, без объединения с СО РАН и совместного продвижения на рынок крупных корпораций ничего не получится. Те же конкурсы мегагрантов - это же не долгосрочное финансирование, на котором можно строить стратегию. Сегодня дали деньги, завтра - нет.

М.П. ФЕДОРУК: - Мы это уже почувствовали. За первые две волны конкурса мегагрантов НГУ выиграл шесть грантов, это один из лучших показателей среди российских университетов. Но как только к конкурсу допустили еще и академические институты, несколько мегагрантов «ушли» в институты СО РАН. Нас опять поставили в положение соперничества. Но мы же прекрасно знаем, что основную работу в науке делают все-таки студенты, аспиранты и молодые ученые...

Кстати, аспиранты - это еще одна острая тема взаимоотношений НГУ и СО РАН. У университета около 250 собственных аспирантов, у СО РАН - около 800, при этом большинство их научных руководителей - преподаватели университета. Отсюда проблемы и споры в связи с аффилиацией научных достижений. Сейчас, когда одним из критериев оценки научной деятельности стало количество публикаций, все очень ревностно стали относиться к аффилиации статей, и часто пеняют нам за то, что мы «приписываем» себе достижения своих преподавателей-совместителей. Это, на мой взгляд, искусственно созданная ситуация. Но нам приходится в ней жить и работать. Осложняет ситуацию и то, что университет собственной сильной научной базы никогда не имел - исторически все лаборатории, оборудование находились в институтах. Но ведь работу выполняют наши преподаватели и часто - наши же студенты, магистранты и аспиранты...

- У Вас есть идеи, предложения, как избежать этого конфликта интересов?

М.П. ФЕДОРУК: - Самое радикальное - это передача всех квалификационных функций университету. Если посмотреть на мировой опыт, это так и происходит. Например, в США академических институтов в нашем понимании нет, есть национальные лаборатории, которые занимаются фундаментальной наукой. Но все $\mathrm{PhD}$, все диссертационные советы сосредоточены в университетах. В НГУ единственный диссертационный совет - 
на экономическом факультете. Все остальные существуют при институтах. Из-за этого, кстати, страдают формальные показатели НГУ в некоторых рейтингах... Как первый шаг необходимо рассмотреть организацию совместной аспирантуры и ученых советов по защите диссертаций.

НГУ и СО РАН, с одной стороны, разорвать невозможно. Но с другой - очень многое построено на личных отношениях. Сегодня это удается, поскольку на ведущих постах в университете и большинстве институтов - выпускники НГУ, но стратегически это неверный подход, и вечно так продолжаться не может. Поэтому формализация наших взаимоотношений с институтами СО РАН, я считаю, это главная проблема и задача на сегодня.

- Раз уж Вы заговорили о выпускниках НГУ в Новосибирском научном иентре... Сейчас, когда мы стремимся на глобальный рынок, может быть, это уже перестало быть больиим плюсом? Нужен приток «свежей крови», идей. И, очевидно, основная нагрузка при этом ложится на университет, который по определению должен быть более мобилен и открыт миру в этом смысле. Что делается в этом направлении?

М.П. ФЕДОРУК: - Абсолютно согласен: отсутствие «свежей крови» является одной из бед Академгородка в целом. В отдельных институтах до $80 \%$ сотрудников составляют выпускники НГУ, и это не есть хорошо. Единственный путь выхода из этой ситуации - приглашение людей извне. Но отсутствие мобильности, в том числе академической - это ведь общероссийская проблема, и особенно остро она ощущается в провинции. Сказываются и разница в уровне зарплат, и проблемы с жильем, и многое другое. Поэтому мы на данном этапе делаем ставку, опять же, на наших выпускников, которые когда-то уехали за рубеж, успели поработать в ведущих научных центрах. Некоторые из них готовы приехать поддержать «альма матер». Речь не идет о том, чтобы вернуться совсем, потому что все они, как правило, успели «врасти корнями» в ту почву - там у них дети, внуки, но, по крайней мере, поработать: прочитать курс лекций, курировать лабораторию и т. д. Например, один из мегагрантов мы получили совместно с Сергеем Константиновичем Турицыным - очень известным и востребованным на Западе ученым. Сегодня в Новосибирском госуниверситете преподают около 50 специалистов из разных стран - Великобритании, Германии, Франции, Японии, США, Испании, Италии, Китая, Нидерландов, 
Турции, Албании, Боснии и Герцеговины и т. д. По итогам 2015 г. количество научных командировок увеличилось в сравнении с прошлым годом более чем вдвое - до 250.

- А молодежь? Аспиранты? Магистранты?

М.П. ФЕДОРУК: - В этом направлении делается очень многое. Основным источником притока иностранцев является совместный китайско-российский институт. В последние годы открыто несколько магистерских англоязычных программ на медицинском, механико-математическом и экономическом факультетах. У нас тесное сотрудничество с Францией - на физфаке, мехмате и экономфаке учатся 15 французских магистрантов. В этом году активизировались обмены с Африкой: набрали на медфак представителей этих стран. Есть совместные программы стажировок с университетом Тохоку - это основной вуз в Японии, который отвечает за академическое сотрудничество с Россией. Подобные программы с Японией реализуют только НГУ, МГУ и ДВФУ.

Мы стараемся многое сделать для повышения мобильности. В том числе, например, ремонтируем старые и строим новые общежития. Потому что нельзя стать университетом мирового уровня, не имея соответствующей инфраструктуры. И, конечно, намерены расширять магистратуру. В наших планах сделать соотношение числа выпускников - бакалавров и магистров - хотя бы 60 на 40, без значительного увеличения количества обучающихся. На 1 сентября 2015 г. в НГУ числилось примерно 6,5 тыс. студентов. Желательно, чтобы из них не менее 2,5 тыс. составляли магистры, но пока эта цифра гораздо меньше: в 2015 г. было 1015 человек. Пытаемся привлекать сильных бакалавров из других вузов, но это не так просто. Во-первых, за хороших студентов идет острая конкуренция, в том числе со столичными вузами. Во-вторых, особенно это касается естественно-научных факультетов, нередко оказывается, что выпускникам даже ведущих вузов не хватает фундаментальной подготовки, чтобы учиться в нашей магистратуре.

- А наши бакалавры охотно остаются в магистратуре НГУ? Многие уезжают?

М.П. ФЕДОРУК: - Не сказал бы, что у нас большой отток. Если кто-то уезжает, то в основном - в Москву. Например, у бакалавров экономфака пользуются популярностью РЭШ, ВШЭ, и они, кстати, там неплохо учатся. Какая-то часть людей уезжает З ЭКО. - 2016. - №2 
с физфака, мехмата. Но определенный конкурс в магистратуру НГУ сохраняется - мы все-таки следим за своим реноме. Например, в 2015 г. бакалавриат мехмата окончили 147 человек, а поступили на первый курс магистратуры 112, включая приезжих из других городов и стран.

В.А. КРЮКОВ: - Можно ведь не только привлекать бакалавров и магистрантов на свою территорию, но и иметь программы в других городах. В тех же Томске, Якутске, Тюмени. Потому что магистратура - это научно-исследовательский профиль образования, к которому многие вузы недостаточно подготовлены. Вы что-то делаете в этом направлении?

М.П. ФЕДОРУК: - Да, но на данном этапе - только с вузами Новосибирска. Пытаемся совместно с ведущими инженерными вузами организовать сетевую инженерную магистратуру, которая будет готовить сильных инженеров-исследователей. Проект курируется региональным министерством образования, подписано соответствующее постановление областного правительства. Но пока мы, можно сказать, еще только приглядываемся друг к другу, ищем точки соприкосновения. В таких совместных проектах нужно, чтобы у каждого была своя «морковка», вот мы и работаем над этим.

- Напоследок давайте немного поговорим о рейтингах. Их, как известно, составляется великое множество. Каждый со своими критериями, подходами. Какие из них являются значимыми, может быть, учитываются в работе, при формировании планов развития?

М.П. ФЕДОРУК: - Понятно, что в зависимости от критериев рейтинга могут быть совершенно разные результаты. Но должен сказать, что какие бы рейтинги ни были, НГУ всегда занимает в них лидирующие позиции среди российских вузов. А ориентируемся на три основных мировых рейтинга: THE, QS и Шанхайский. Доверие к первому из них в 2015 г. было немного подорвано, когда из-за смены критериев и системы подсчета некоторые университеты «подпрыгнули» чуть ли не на несколько сотен позиций. Тем не менее этот рейтинг уже два года подряд относит нас к ТОП-100 университетов по физическим наукам. Шанхайский рейтинг является наиболее консервативным из трех. Там подобные скачки невозможны в принципе, поскольку учитываются, например, такие «однозначные» показатели, как количество нобелевских и филдсовских лауреатов-выпускников вуза, число публикаций 
в Science и Nature. Понятно, что попасть в этот рейтинг непросто. Например, у нас нет ни одного нобелевского лауреата, хотя наш выпускник - Ефим Исаакович Зельманов - лауреат Филдсовской премии. Но, с другой стороны, новосибирскому университету всего 56 лет. А, например, в МІТ первый нобелевский лауреат появился спустя 85 лет после создания. Пока мы в этом рейтинге занимаем 536-е место. Это третий-четвертый результат из российских вузов после МГУ и СПГУ, которые входят в ТОП-500, ну и примерно равные позиции с МФТИ. Но все-таки за двумя столичными университетами история: МГУ недавно отметил 250-летний юбилей, а Санкт-Петербургскому университету - уже 290 , он основан еще Петром 1. Понятно, что большая часть нобелевских лауреатов России - из этих университетов, да и у МФТИ в 2010 г. появилось два нобелевских лауреата.

Поэтому главный наш ориентир - рейтинг QS. B нем, правда, тоже изменилась методология оценки, но мы по отдельным направлениям имеем там очень неплохие позиции и даже продвинулись по итогам 2015 г. на 11 пунктов в общем рейтинге.

- Как-то это отражается на повседневной жизни универcumema?

М.П. ФЕДОРУК: - Отражается прежде всего благодаря тому, что создается репутация. К нам охотнее приезжают профессора и студенты из других городов и стран. НГУ очень прилично выглядит не только на фоне российских вузов, но даже на мировом уровне - вы представляете, сколько в мире университетов? Я бы сказал, что по сути НГУ всегда был в ТОП-100, просто это не всегда отражается в формальных показателях. Во всяком случае, из трех показателей, по которым нас опережают ведущие вузы - возраст, число нобелевских лауреатов и репутация - это то, что поддается нашему непосредственному влиянию. Если мы будем двигаться в правильном направлении, всё у нас получится.

Материал подготовила Э.Ш. ВЕСЕЛОВА, кор. «ЭКО» 